\title{
A real world feasibility trial of the PLAYshop: a brief intervention to facilitate parent engagement in developing their child's physical literacy
}

\author{
Cassandra Lane \\ The University of Newcastle \\ Valerie Carson \\ University of Alberta \\ Kayla Morton \\ University of Victoria \\ Kendra Reno \\ University of Victoria \\ Chris Wright \\ University of Victoria \\ Madison Predy \\ University of Alberta \\ Patti-Jean Naylor ( $\nabla$ pjnaylor@uvic.ca ) \\ University of Victoria https://orcid.org/0000-0002-4799-2751
}

Research

Keywords: Physical literacy, parent, child, fundamental movement skills

Posted Date: December 9th, 2020

DOI: https://doi.org/10.21203/rs.3.rs-23520/v2

License: (c) This work is licensed under a Creative Commons Attribution 4.0 International License. Read Full License 


\section{Abstract}

Background: Development of physical literacy, defined as "the motivation, confidence, physical competence, knowledge and understanding to value and take responsibility for engagement in physical activities for life", can support children's physically active behaviors and consequent health benefits. Little research exploring interventions to improve children's physical literacy exist, although substantive evidence shows parents play a key role in children's physically active behaviors and development of fundamental movement skills. The purpose of this study is to explore a novel, physical literacy intervention designed to assist parents to engage with their child in purposeful play; play that facilitates the development of physical literacy.

Methods: The PLAYshop was a 75-minute workshop to build parents' self-efficacy to support their child's physical literacy through interactive activities and educational messages as well as educational resources focused on core physical literacy concepts. We collected quantitative pre- and post-workshop surveys of parents' satisfaction, knowledge, confidence and intention to adopt practices as well as qualitative follow-up implementation focused interviews from both parents and facilitators. We used paired t-tests to examine changes in parents' self-reported physical literacy knowledge and confidence and thematic analysis of interviews to explore workshop feasibility.

Results: Six workshops were delivered to 33 parents of young children (3-8 years of age). Twenty-three parents completed both pre- and post-workshop surveys. Follow-up interviews were completed with 11 parents and four workshop facilitators. Parents' self-reported knowledge and confidence to support their child's physical literacy development significantly increased after PLAYshop participation. Further, the majority of parents were satisfied with the workshop and motivated to apply workshop learnings at-home with their child. Workshop facilitators identified seven workshop strengths (e.g., workshop champions and skilled facilitators) and four challenges (e.g., recruitment and unfavorable spaces).

Conclusions: The PLAYshop was perceived positively by parents and facilitators and appeared to improve parent self-efficacy and intention to promote physical literacy with their child. Recruitment and attendance were key implementation challenges. The findings from this real world trial address an important evidence gap, highlighting areas for adaptations to improve the intervention and recruitment and suggesting that the PLAYshop is ready for efficacy testing in a more rigorous randomized controlled trial.

\section{Background}

Physical activity is critically important to the development of young children as it improves cognitive and motor skill development, psychosocial health, social connectedness, and cardio metabolic health and reduces adiposity (Carson et al., 2017; Tremblay et al., 2012) and risk of chronic disease in adulthood (Craigie, Lake, Kelly, Adamson, \& Mathers, 2011). Physical inactivity has emerged as a public health pandemic (Kohl 3rd et al., 2012) and internationally the prevalence of children participating in sufficient levels of physical activity remains low (Aubert et al., 2018). In response, researchers have developed and tested the effectiveness of numerous childhood physical activity interventions (Messing et al., 2019). Amidst some success, their impact on children's levels of physical activity appears limited (Metcalf, Henley, \& Wilkin, 2012) and several research gaps remain.

Physical literacy offers a relatively new and promising approach for childhood physical activity interventions (Cairney, Dudley, Kwan, Bulten, \& Kriellaars, 2019). It is defined by the International Physical Literacy Association as "the motivation, confidence, physical competence, knowledge and understanding to value and take responsibility for engagement in physical activities for life" (IPLA, 2017). The novelty of physical literacy lies in the equal importance assigned to four key domains: affective (motivation and confidence), cognitive (knowledge and understanding), social (relationships and social networks) and physical capabilities (e.g. motor skill competence and fundamental movement skills; FMS) (Edwards, Bryant, Keegan, Morgan, \& Jones, 2017; Richard et al., 2019). Physical literacy is an antecedent to improve and maintain physical activity participation and consequent health benefits (Cairney et al., 2019; Edwards et al., 2017) - which makes it particularly important to begin to develop early in the life course (Sport for Life, 2019). Parents' meaningful engagement in their child's physical literacy journey is considered critical (Sport for Life, 2019) due to their influence on their child's physical activity-related behaviors; supported by systematic review evidence.

In a 2016 systematic review of family-based physical activity interventions, 31 of the 47 included studies demonstrated a significant positive effect on children's physical activity levels (Brown et al., 2016). A systematic review of the determinants of physical activity in children aged 0-6 years found that parent monitoring was the only factor consistently associated with children's physical activity (Hesketh, O'Malley, et al., 2017). Lastly, a synthesis of results from 39 high-quality reviews (Messing et al., 2019) provided strong evidence that parents play a key role in promoting child physical activity across various community settings. Recently, Rhodes and colleagues (Ryan $\mathrm{E}$ Rhodes, Perdew, \& Malli, 2020) further explored this topic by systematically reviewing the correlates of parental support on child physical 
activity. Out of the twenty correlates identified in 19 unique data sets; co-participation, logistical support and encouragement were the most common elements of interventions with a positive effect on children's physical activity levels.

Although previous systematic reviews did not report on physical literacy, many studies included for review examined parent-focused interventions with an emphasis on FMS - a key part of physical literacy (Barnett et al., 2016; Zeng, Johnson, Boles, \& Bellows, 2019) often used synonymously (Edwards et al., 2017). For example, the three month Healthy Dads Healthy Kids (HDHK) program adopted FMS as the exclusive focus for one of the four, 75-minute father/child practical sessions (Morgan, Lubans, Plotnikoff, et al., 2011). Similarly, the eightweek Dads and Daughters Exercising and Empowered (DADEE) program (Morgan et al., 2019) and the mother-daughter MADE4Life program (Barnes, Plotnikoff, Collins, \& Morgan, 2015) each devoted at least one practical session to FMS. FMS was an explicit outcome measure within only one intervention trial: a 2018 randomized controlled trial (RCT) of DADEE that found significant improvements in daughters' FMS proficiency (Morgan et al., 2019). FMS competence was objectively assessed via scores of daughters' performance in six object control skills (kicking, catching, striking a stationary ball, stationary dribble, overhand throw, and underhand throw). Compared to controls, daughters in the intervention had significantly higher object control scores post-intervention $(p<.001)$ that were sustained at 9month follow up $(p \leq .002)$.

Positive findings for physical activity-related outcomes were found in trials of all interventions: fathers in DADEE significantly improved in physical activity parenting practices compared to controls (Morgan et al., 2019); children in HDHK significantly increased in level of physical activity compared to controls (Morgan, Lubans, Callister, et al., 2011); and mothers in MADE4Life reported positive behavior change as a result of the program (Barnes et al., 2015). Further, all of these programs appeared feasible, with high attendance and ratings of program satisfaction made by fathers in HDHK (Morgan, Lubans, Callister, et al., 2011) and DADEE (Morgan et al., 2019), as well as high ratings of program quality and session content made by mothers in MADE4Life (Barnes et al., 2015).

These parent-focused interventions inclusive of FMS appear to have a meaningful impact on children's physical activity. However, they required a significant time commitment from parents (multiple sessions over the course of 2-3 months) and were resource intensive. A simplified intervention may be more accessible for time-restricted parents and be more amenable for scale up (World Health Organization \& ExpandNet, 2011). It is also unclear whether the aforementioned interventions had any impact on parent self-efficacy - an important component of behavior change (Bandura, 1986) also linked to children's physical activity levels (Smith et al., 2010).

Increasing parent self-efficacy (knowledge, confidence and capacity) to carry out activities that promote physical literacy may provide children with a foundation for development in this area. No research to-date has explored a brief parent-focused physical literacy program as an intervention option. This paper aims to address this evidence gap by assessing the feasibility of a novel theory-based program aimed to build parents' self-efficacy in assisting their child to develop physical literacy and acquire physical activity through play.

\section{The PLAYshop program}

The PLAYshop was originally designed by a lead member of the research team in partnership with a representative from a community agency that provided physical literacy opportunities for children and youth and professional development (Pacific Institute for Sport Excellence; PISE). It was first trialled in two community settings to test the approach (core physical literacy content, theoretically driven behaviour change and adult education techniques) and feasibility of the format (recruitment, delivery model, etc.). The intervention was then refined for preliminary evaluation (feasibility testing) in a research context. It was designed with the intent to be scaled up if proven effective within a fully-powered efficacy trial, as per WHO recommendations (World Health Organization \& ExpandNet, 2011).

The program involved one face-to-face, 75-minute group workshop and the provision of educational materials. Workshops were delivered to up to 15 parents, in community settings, by the lead researcher and/or a trained graduate student; each of whom held degrees in physical and health education. The lead researcher had experience in the development of physical literacy and physical activity habits, community-based health promotion and adult education techniques. The graduate student workshop facilitator was trained by the lead researcher, had completed a two-hour physical literacy education session, and was included in an embedded professional development workshop training approach prior to delivering a full workshop. Facilitator training included first observing the workshop, then incremental responsibility (delivering portions of the workshop under the supervision of the lead researcher), and lastly delivering significant portions of the workshop under supervision. Workshop format and content were guided by the workshop template that was developed by the lead researcher in collaboration with community physical literacy experts (PISE) using evidence-based behaviour change techniques (Michie, Van Stralen, \& West, 2011), adult education and training practices, as well as recommendations and material from international experts in physical literacy development (Sport for Life, 2019; Tremblay et al., 2018).

The specific objectives of the PLAYshop were: 
- to enhance parents' understanding of physical activity and physical literacy and their role in facilitating it;

- to expose parents to a number of activities and resources that could help them support the development of a wide range of movement skills and increase physical activity; and

- to increase parents' confidence in facilitating playful activities by engaging them in the activities (experiential learning) and providing key messages and modeling approaches that align with and promote the development of physical literacy (competence, motivation, confidence, and valuing physical activity).

We employed a systematic process of program design based on Bandura's social cognitive theory (SCT) (Bandura, 1986) and the Behavior Change Wheel (BCW; a synthesis of 19 behavior change frameworks) (Michie et al., 2011). Several constructs of SCT (e.g., observational learning, reinforcement and intentions) were targeted throughout intervention design, as well as development of program components and data collection tools. Our primary focus was self-efficacy - a construct unique to SCT that aligned with our aim to improve parent's knowledge and confidence to perform target behaviors.

The BCW was employed to identify specific strategies to support parents to adopt target behaviours to facilitate cross-jurisdiction knowledge exchange. First, we identified possible barriers and/or enablers to parent's purposeful play with their child via reviews of the literature and discourse with parents during the development workshops and among the research team. Examples of identified factors that may influence parents to adopt target behaviours include time (Hesketh, Lakshman, et al., 2017; Martin-Biggers et al., 2015), available resources (Hesketh, Lakshman, et al., 2017) and confidence (Smith et al., 2010). We then classified each factor according to the COM-B model as either capability, opportunity or motivation. A program logic model is provided in Figure 1, and the behaviour change techniques to address the identified barriers and enablers are detailed in Table 1.

Table 1-Description of strategies mapped to the relevant COM-B factors and behavior change techniques 


\begin{tabular}{|c|c|c|c|c|}
\hline $\begin{array}{l}\text { Implementation } \\
\text { strategy }\end{array}$ & $\begin{array}{l}\text { Intervention } \\
\text { function }\end{array}$ & $\begin{array}{l}\text { Barriers and } \\
\text { enablers } \\
\text { addressed } \\
\text { (COM-B) }\end{array}$ & $\begin{array}{l}\text { Behaviour } \\
\text { change } \\
\text { technique } \\
\text { employed }\end{array}$ & Detailed description \\
\hline \multirow[t]{4}{*}{$\begin{array}{l}\text { 1. Conduct } \\
\text { educational } \\
\text { training }\end{array}$} & \multirow[t]{4}{*}{$\begin{array}{l}\text {-Education } \\
\text {-Training } \\
\text {-Modelling } \\
\text { - } \\
\text { Enablement } \\
\text {-Persuasion }\end{array}$} & $\begin{array}{l}\text { Parent } \\
\text { knowledge } \\
\text { and } \\
\text { confidence } \\
\text { (psychological } \\
\text { capability) }\end{array}$ & \multirow{4}{*}{$\begin{array}{l}\text {-information } \\
\text { about physical } \\
\text { literacy and } \\
\text { positive } \\
\text { outcomes for } \\
\text { child } \\
\text {-instruction on } \\
\text { how to perform } \\
\text { the behaviour(s) } \\
\text {-instruction on } \\
\text { how to perform } \\
\text { the behaviour(s) } \\
\text { using common } \\
\text { household items } \\
\text {-demonstration } \\
\text { of the } \\
\text { behaviour(s) } \\
\text {-practice of the } \\
\text { behaviour(s) } \\
\text {-problem } \\
\text { solving } \\
\text {-identification } \\
\text { of self (parent) } \\
\text { as role model to } \\
\text { child } \\
\text {-verbal } \\
\text { persuasion } \\
\text { about capability } \\
\text {-principles of } \\
\text { and ideas for } \\
\text { modifications to } \\
\text { support the } \\
\text { parent in } \\
\text { meeting the } \\
\text { child's needs in } \\
\text { terms of current } \\
\text { ability and } \\
\text { motivations } \\
\end{array}$} & \multirow{4}{*}{$\begin{array}{l}\text { A } 75-\text { minute workshop for parents, delivered in an } \\
\text { accessible community site (e.g., school, sport club or } \\
\text { recreation center) by a facilitator with a background in } \\
\text { physical literacy. Parents are introduced to the core } \\
\text { concepts of physical literacy (motivation, competence, } \\
\text { confidence, valuing, ) via education, group discussion, } \\
\text { and active participation in FMS-based activities. Parents } \\
\text { are provided with modifications to perform activities 'at } \\
\text { home'. }\end{array}$} \\
\hline & & $\begin{array}{l}\text { Parent } \\
\text { perceived } \\
\text { ability to } \\
\text { implement } \\
\text { change } \\
\text { (physical } \\
\text { capability) }\end{array}$ & & \\
\hline & & $\begin{array}{l}\text { Lack of } \\
\text { available } \\
\text { resources } \\
\text { and/or time } \\
\text { to engage in } \\
\text { purposeful } \\
\text { play with } \\
\text { child } \\
\text { (physical } \\
\text { opportunity) }\end{array}$ & & \\
\hline & & $\begin{array}{l}\text { Lack of } \\
\text { prioritising } \\
\text { child's } \\
\text { physical } \\
\text { literacy } \\
\text { (reflective } \\
\text { motivation) }\end{array}$ & & \\
\hline \multirow[t]{2}{*}{$\begin{array}{l}\text { 2. Distribute } \\
\text { educational } \\
\text { resources }\end{array}$} & \multirow[t]{2}{*}{$\begin{array}{l}\text {-Education } \\
\text { - } \\
\text { Enablement }\end{array}$} & $\begin{array}{l}\text { Parent } \\
\text { knowledge } \\
\text { and abilities } \\
\text { (physical and } \\
\text { psychological } \\
\text { capability) }\end{array}$ & \multirow{2}{*}{$\begin{array}{l}\text {-information } \\
\text { about physical } \\
\text { literacy and } \\
\text { positive } \\
\text { outcomes for } \\
\text { child } \\
\text {-problem } \\
\text { solving } \\
\text {-messages } \\
\text { about } \\
\text { addressing } \\
\text { multiple } \\
\text { developmental } \\
\text { goals through } \\
\text { physical play } \\
\text { like numeracy } \\
\text { and literacy } \\
\text { through singing } \\
\text { and counting }\end{array}$} & \multirow[t]{2}{*}{$\begin{array}{l}\text { Several resources are provided to parents at workshop } \\
\text { conclusion: Canada's } 24 \text {-hour movement guidelines for } \\
\text { children and youth, cards with various activity ideas, } \\
\text { and a one-page physical literacy information handout. }\end{array}$} \\
\hline & & $\begin{array}{l}\text { Lack of } \\
\text { available } \\
\text { resources } \\
\text { and/or time } \\
\text { to engage in } \\
\text { purposeful } \\
\text { play with } \\
\text { child } \\
\text { (physical } \\
\text { opportunity) }\end{array}$ & & \\
\hline
\end{tabular}

\section{Methods}

Trial design

Six physical literacy workshops (the PLAYshop) were delivered at different times in schools ( $\mathrm{n}=4)$ and sport clubs ( $\mathrm{n}=2)$ within two Canadian jurisdictions. This non-randomized study used a one-arm, concurrent nested approach with quantitative data collected through pre- and post-workshop surveys and qualitative data collected through follow-up telephone interviews of parents and PLAYshop facilitators. Human research ethics approval for the study was obtained from the University of Victoria (\#16-444) and University of Alberta (\#00093764). 


\section{Participants}

We invited parents (fathers and/or mothers) or guardians of young children (ideally 3-8 years of age) to participate in the PLAYshop using e-flyers distributed through the community networks of the schools, recreation centers, and local sports clubs. Siblings of any age were welcome to join and be involved in the workshop. All parents that showed up on the delivery day were invited to partake in the program, with data obtained only from one parent and PLAYshop facilitators who signed a consent form.

\section{Data collection}

Quantitative data: Pre- and post-workshop surveys of parents collected information about demographics and key study outcomes. Surveys were developed for the study by the research team and guided by SCT (Bandura, 1986). Our primary outcome measures were (a) parent knowledge of physical literacy and its key components (physical literacy; locomotor skills, manipulative skills, balance and stability, facilitating physical activities) and (b) parent confidence in promoting physical literacy (providing opportunities for exploration and free play; adapting activities for child's age/ability; creating a home environment that encourages physical activity; and limiting sedentary behaviours). Instrument sub-scales were adapted from the Activity Support Scale for Multiple Groups (ACTS-MG) (Davison, Li, Baskin, Cox, \& Affuso, 2011) and the ParticipACTION Family Physical Activity Questionnaire (Ryan E. Rhodes \& Rebar, 2017). Questions used 5-point Likert scale items to measure both parent knowledge ( $1=$ no knowledge to $5=$ a lot of knowledge), and parent confidence ( $1=$ no confidence to 5 = a lot of confidence). The post-workshop survey included an additional section on workshop experience with questions relating to parents' satisfaction with workshop delivery, whether the content was new to them, and the usefulness of training. Facilitators distributed the pre-workshop survey for completion by parents on-site, immediately prior to workshop delivery. A member of the research team then emailed participants the post-workshop survey to complete one day following workshop delivery.

Qualitative data: A member of the research team conducted 10-15 minute semi-structured follow-up interviews of parents approximately two months after workshop delivery (follow-up). This time period was chosen to provide parents sufficient time to implement a number of workshop activities with their child and to determine the level of implementation over the short term. Interviews were composed of openended questions to assess the feasibility of the PLAYshop, including amenability with workshop teachings, applicability of workshop content, and the ease and/or barriers to implementing learnings with their child/children. A researcher independent of the PLAYshop then conducted 10-15 minute semi-structured interviews with facilitators to assess the enablers and barriers to workshop implementation, as well as explore possible modifications to enhance workshop efficacy and useful components that should remain unchanged.

\section{Data analysis}

Quantitative data: We used SPSS Version 21.0 to analyze all quantitative data. Demographics and descriptive statistics described the population and baseline levels of knowledge, confidence and motivation. Changes in parents' physical literacy knowledge and confidence from baseline to follow-up were analyzed using paired t-tests. Statistical significance was defined as $p<0.05$. Measures of frequency (expressed as valid percentages) were calculated to analyze parents' satisfaction with workshop content and delivery and post-workshop intent to participate in physical activities with their children.

Qualitative data: We analyzed qualitative data following principles of framework analysis as detailed by Gale and colleagues (Gale, Heath, Cameron, Rashid, \& Redwood, 2013). Two researchers generated themes for parent and facilitator interviews using the following steps: (1) co-coding a subset of transcripts, (2) generating a flexible coding framework, (3) applying this framework to subsequent transcripts, (4) assigning codes to categories, and (5) developing these into themes and sub-themes. The research pair discussed and reached agreeance on any variability that arose during this process. Where consensus could not be achieved, a third member of the research team assisted in final decisions.

\section{Results}

\section{Sample}

The study sample consisted of approximately 1500 families of younger elementary aged-children families (estimated based on sizes of school classes and number of sport club members). We recruited 35 parents from 33 different families to participate in the PLAYshop. One parent from each family completed the pre-workshop survey ( $\mathrm{n}=33$; mean age $=38.45$ years; $24.2 \%$ male, $75.8 \%$ female) however 10 did not return the emailed post-workshop survey. Only data from the 23 parents who completed surveys at both time points were included for analysis. Eleven parents also completed the two-month follow-up telephone interview; the remainder declined to participate or were unreachable by phone. The average number of children per household was 1.85. All four PLAYshop facilitators completed the facilitator interview. 
Valid quantitative data for comparison were obtained from pre- and post-workshop surveys completed by 23 parents. Paired t-test analysis showed a significant increase across all measures of parents' self-reported knowledge from pre- to post-workshop ( $p \leq 0.027)$. Figure 1 displays parents' mean self-reported level of knowledge pre-and post-intervention in regards to key physical literacy knowledge variables. Parents' mean level of knowledge significantly improved for physical literacy $(1.25$ [SD = 1.42], $p=0.011)$; locomotor skills $(1.14$ [SD = $1.01], p=0.000)$; manipulative skills (e.g., catching, striking, kicking, hitting, throwing) $(1.0$ [SD $=1.21], p=0.002)$; balance and stability $(0.95[S D=1.16], p=0.001)$; and facilitating physical activities $(0.81[1.47], p=0.02)$.

Paired t-test analysis also showed a significant increase across all measures of parents' self-reported level of confidence for initiating and implementing physical literacy activities with their children from pre-workshop to post-workshop $(P<.05)$. Significant improvements were found for parents' mean level of confidence to provide their child with opportunities for exploration and free play $(0.55$ [SD $=0.76$ ], $p=$ $0.004)$; to adapt physical activities for different ages and abilities (1.0 [SD $=0.86], p=0.000)$; to create a home environment that encourages physical activity $(0.71$ [SD $=0.72$ ], $p=0.000)$; and to limit sedentary behaviors such as screen time and prolonged sitting $(0.48$ $[S D=0.75], p=0.009$ ).

\section{Parent workshop experience}

Of the 23 parents who completed post-workshop surveys, the majority reported that they were extremely satisfied with the workshop content $(72.7 \%)$ and delivery $(68.2 \%)$, with no parent reporting anything less than somewhat satisfied (range 3-5). Most parents also found the workshop training useful (59.1\%). The workshop content was reported as "somewhat new" by $49 \%$ of parents and "very new" by $28.6 \%$. Most parents (65.2\%) were motivated to do physical activity with their children within two weeks of the workshop delivery, and $43.5 \%$ strongly disagreed that performing physical activities with their child/children within two weeks of the workshop would be difficult.

Thematic analysis of the follow-up semi-structured interviews of parents $(n=11)$ identified five key themes in relation to implementing the physical literacy activities and concepts (table 2). Sub-themes are also displayed with illustrative parent quotes. Prominent facilitators were the ease of access/simplicity of activities introduced in the PLAYshop and the enthusiasm of children. A further prominent theme was life barriers getting in the way (i.e., time, routine, and motivation). Parents further suggested that having children of varying developmental stages and receding memories of workshop content over time may pose as an obstacle to using lessons from the PLAYshop.

Table 2 - Parent feedback in relation to workshop experience and motivation

\begin{tabular}{|c|c|c|}
\hline Theme & Sub-Theme & Supporting Quotes \\
\hline Simple to use & $\begin{array}{l}\text { - Simple props/supplies } \\
\text { - Use what's available } \\
\text { - Accessible }\end{array}$ & $\begin{array}{l}\text { 1. "Simple and straightforward" } \\
\text { 2. "didn't require a lot of equipment" } \\
\text { 3. "access is so easy" }\end{array}$ \\
\hline $\begin{array}{l}\text { Life gets in } \\
\text { the way }\end{array}$ & $\begin{array}{l}\circ \text { Time } \\
\circ \text { Motivation } \\
\circ \text { Implementing a } \\
\text { routine } \\
\end{array}$ & $\begin{array}{l}\text { 1. "Setting a side specific time. Scheduling is always hectic" } \\
\text { 2. "Nothing other than my laziness" } \\
\text { 3. "Time probably number } 1 \text { " }\end{array}$ \\
\hline $\begin{array}{l}\text { Kids are } \\
\text { interested }\end{array}$ & $\begin{array}{l}\text { - Skills versus } \\
\text { outcomes focused }\end{array}$ & $\begin{array}{l}\text { 1. "Not make it about how far but the skills level of it" } \\
\text { 2. "more about technique rather than distance" } \\
\text { 3. "Interested, he wants to do it" } \\
\text { 4. "See their excitement and get excited about it" }\end{array}$ \\
\hline $\begin{array}{l}\text { Children } \\
\text { differ }\end{array}$ & $\begin{array}{l}\text { - Sibling development } \\
\text { stages }\end{array}$ & 1. "I usually have both kids at the same time. Difference between kids" \\
\hline $\begin{array}{l}\text { We need } \\
\text { reminding }\end{array}$ & $\begin{array}{l}\text { - Information fades } \\
\text { - No reminders }\end{array}$ & $\begin{array}{l}\text { 1. "Hard to recall everything. Maybe a follow-up booklet or an outline of } \\
\text { theories for activities" } \\
\text { 2. "forget activities" }\end{array}$ \\
\hline
\end{tabular}

\section{Facilitator feedback}

Thematic analysis of the semi-structured interviews of workshop facilitators generated two major categories - one relating to strengths and successes (see Table 3) and one relating to challenges and areas for improvement (see Table 4). Each major category was divided into seven themes and four themes respectively, with some themes fitting within both. For instance, the presence of a champion assisted in the success of some workshops while the absence of a champion appeared as a key challenge for others. Similarly, children attending the 
workshops served as both a challenge (occasional distraction) and strength (assisted with experiential learning and recruitment), and space for movement also served as either a challenge (inadequate space) or strength (ample space). Facilitator expertise, workshop content and parents' positive response to the workshop all emerged as workshop strengths while the need to support parents after the workshop emerged as an area for improvement.

Table 3 - Workshop strengths and successes from the perspective of workshop facilitators

\begin{tabular}{|c|c|}
\hline \multicolumn{2}{|c|}{ Workshop Strengths and Successes } \\
\hline Theme & Quotes \\
\hline \multirow{2}{*}{$\begin{array}{l}\text { Having a } \\
\text { Parent or } \\
\text { Teacher } \\
\text { Champion }\end{array}$} & $\begin{array}{l}\text { F1: The } 2 \text { schools where we had the most effective recruitment, we had a super engaged parent that did all } \\
\text { the recruiting for us. }\end{array}$ \\
\hline & $\begin{array}{l}\text { F2: So when people- so for one school that we did [the workshop] in we had a parent advocate in that } \\
\text { school who wanted to bring it in and so that really helped because then the turn out for that [workshop] } \\
\text { was much better ... }\end{array}$ \\
\hline \multirow[t]{3}{*}{$\begin{array}{l}\text { Children } \\
\text { Attending } \\
\text { Workshops }\end{array}$} & $\begin{array}{l}\text { F4: I think it's important to keep- to have at least part of [the workshop] with their kids. Like get [parents] } \\
\text { involved with their own kids right off the bat .... that eliminates big barriers too...then parents don't have to } \\
\text { worry about getting child care or anything like that. }\end{array}$ \\
\hline & $\begin{array}{l}\text { F1: because we got feedback from parents in one of the schools where they weren't sure if they could bring } \\
\text { their children .... They felt [not including kids] reduced attendance ..... }\end{array}$ \\
\hline & $\begin{array}{l}\text { F2: Umm, so we did allow people to bring their kids. which was good because we had enough facilitators } \\
\text { there to break off into } 2 \text { groups... and then we would come back as a big group. So I think that was ... } \\
\text { helpful and then we could see how parents are actually interacting with the kids and they can try things } \\
\text { right then and there. }\end{array}$ \\
\hline \multirow{4}{*}{$\begin{array}{l}\text { Skilled } \\
\text { Workshop } \\
\text { Facilitators }\end{array}$} & \\
\hline & $\begin{array}{l}\text { F1: So, you need to be able to riff- on the day you need to be able to riff a bit. Oh and here's an extension, } \\
\text { because sometimes a family comes and they actually have a } 8 \text { year old there and a } 5 \text { year old, and the } \\
\text { activity for the } 5 \text { year old and the } 8 \text { year old are different. And you need to be able to demonstrate those } \\
\text { quick revisions on the fly for the parent. }\end{array}$ \\
\hline & $\begin{array}{l}\text { F3: And I thought that obviously [Facilitator 1] is great at adjusting... [and] in the moment going like "This } \\
\text { isn't working, we should do something else", so I think that was great. So I think not sticking to the plan } \\
\text { too well was really what made the PLAYshop work when we did it. }\end{array}$ \\
\hline & $\begin{array}{l}\text { F4:... also one of the things I witnessed when I sat in on other [workshops] was the kind of optimism and } \\
\text { enthusiasm and energy from a facilitator. So, that really has an impact on how engaged the parents become } \\
\text { themselves. and how enthusiastic and energetic they are. }\end{array}$ \\
\hline \multirow{3}{*}{$\begin{array}{l}\text { Separating } \\
\text { Parents and } \\
\text { Children }\end{array}$} & $\begin{array}{l}\text { F1: So, reflection and discussion is an important piece of the adult education experience and so that also } \\
\text { needs the kids pulled away }\end{array}$ \\
\hline & $\begin{array}{l}\text { F2: Umm, so we did allow people to bring their kids. Um, which was good because then we had enough } \\
\text { kinda facilitators there to break off into } 2 \text { groups. So when we needed to speak to the parents by } \\
\text { themselves we could, and then someone would play games with the kids and then we would come back as a } \\
\text { big group. }\end{array}$ \\
\hline & F4: \\
\hline \multirow{3}{*}{$\begin{array}{l}\text { Conducive } \\
\text { Spaces }\end{array}$} & F1: \\
\hline & $\begin{array}{l}\text { F3: We did [the workshop]- the ones that I helped out with- we did in } 2 \text { elementary school gyms and that's } \\
\text { like the perfect amount of space. }\end{array}$ \\
\hline & $\begin{array}{l}\text { F4: ... just really making sure that [the space] is a setting conducive to movement and to physical literacy } \\
\text { type game[s] and play. }\end{array}$ \\
\hline \multirow{3}{*}{$\begin{array}{c}\text { Parent } \\
\text { Response } \\
\text { and } \\
\text { Engagement }\end{array}$} & F1: So, the parents were really enthusiastic. ... They asked questions. .... they were very engaged. \\
\hline & $\begin{array}{l}\text { F4: The parents seemed to receive [the workshop] well. We did have some parents with their kids there and } \\
\text { the kids [also] seemed to really be engaged and it was a positive atmosphere. }\end{array}$ \\
\hline & F2: \\
\hline \multirow{4}{*}{$\begin{array}{l}\text { Workshop } \\
\text { Content }\end{array}$} & F1: I \\
\hline & $\begin{array}{l}\text { F2: I think the actual content of [the workshop] was good, parents seemed to like that. So I wouldn't } \\
\text { change necessarily that aspect. }\end{array}$ \\
\hline & $\begin{array}{l}\text { F4: ... and then those key messages... watching some of the other workshops that were facilitated primarily } \\
\text { by [Facilitator 1] really the emphasis on those key messages about being playful and fun but also [using the } \\
\text { play] in order to develop those skills and the importance behind that. }\end{array}$ \\
\hline & \\
\hline
\end{tabular}

Table 4 - Workshop challenges and areas for improvement from the perspective of workshop facilitators 


\begin{tabular}{|c|c|}
\hline \multicolumn{2}{|c|}{ Workshop Challenges and Areas for Improvement } \\
\hline Theme & Quotes \\
\hline \multirow{6}{*}{$\begin{array}{l}\text { Workshop } \\
\text { Recruitment } \\
\text { and } \\
\text { Attendance }\end{array}$} & F1: Recruitment. It is so difficult getting the parents [to the workshop]. It is very random. So typically when \\
\hline & $\begin{array}{l}\text { you're recruiting in all these settings you're going through a third party, like the parent advisory committee } \\
\text { person, inviting the parents through their network or the school principal or the sport club technical }\end{array}$ \\
\hline & $\begin{array}{l}\text { director. So, you have to rely on somebody to send out the notices to the list. So that broke down in some } \\
\text { cases, but not all. }\end{array}$ \\
\hline & F3: I think participation was the biggest one... it's easy enough to put it out there and say this is gonna \\
\hline & $\begin{array}{l}\text { happen and I think in theory like people want to know this sort of stuff ... but like when it comes time to } \\
\text { actually deliver the programs a lot of those like "maybes, ya sortas" turn into no-shows. }\end{array}$ \\
\hline & \\
\hline \multirow{3}{*}{$\begin{array}{l}\text { Unfavorable } \\
\text { Spaces }\end{array}$} & F1:...outside space is problematic I would suggest that the workshop should be done indoors and mostly \\
\hline & $\begin{array}{l}\text { because we use a lot of balloons and light things and they blow away. The second thing is the ability to } \\
\text { bound your space. It's a bit chaos-y. You need an ability to bound your space }\end{array}$ \\
\hline & $\begin{array}{l}\text { F4:... ya the classroom was a little broken [up] because of all the chairs and the tables and I remember } \\
\text { thinking that it would be better had I pushed like the stuff aside and just created a more open inviting } \\
\text { atmosphere. }\end{array}$ \\
\hline \multirow{4}{*}{$\begin{array}{l}\text { Children as } \\
\text { a } \\
\text { Distraction }\end{array}$} & \\
\hline & F3: I think we tried to do it all together and when you're- it's like 7 o'clock after school and kids are \\
\hline & $\begin{array}{l}\text { expecting to be like playing games and you're trying to explain things to the parents while the kids are just } \\
\text { standing there and watching you do it, you lose a lot of that attention because the parents are now worried } \\
\text { about what the kids are doing instead of what you're explaining to them about. }\end{array}$ \\
\hline & $\begin{array}{l}\text { F4: .... when the parents that had small children with them, I think it was harder, it was more difficult for } \\
\text { them to (pause) focus and really get the most out of the workshop.... }\end{array}$ \\
\hline \multirow{4}{*}{$\begin{array}{l}\text { Supporting } \\
\text { Parents } \\
\text { after the } \\
\text { Workshop }\end{array}$} & F1:... I would do a let's make activity and they would leave with the piece of equipment ...... We did do a \\
\hline & $\begin{array}{l}\text { [simple] handout, ... but a more professional handout and a web resource where they could go to find some } \\
\text { simple ideas probably would help. }\end{array}$ \\
\hline & \\
\hline & $\begin{array}{l}\text { F4: [The workshop] is engaging and parents get motivated but then once they leave- what are the chances } \\
\text { that it's sustained that kind of you know learning and positive energy. ... so I think some sort of- follow-up, } \\
\text { some sort of sustainability type strategy just to prompt that continued behaviour. }\end{array}$ \\
\hline
\end{tabular}

\section{Discussion}

We conducted a small, real world uncontrolled study to assess the feasibility of a brief, parent-focused intervention aimed at enhancing the knowledge, confidence, skills and resources necessary to support them in developing their child's physical literacy through play. According to our results, the majority of parents who partook in the PLAYshop were highly satisfied with both workshop delivery and content. It also appeared to have a positive impact on parents' knowledge, confidence, and engagement in purposeful play with their child/children. Compared to pre-workshop measures, post-workshop surveys of parents immediately following program delivery showed significantly higher levels of knowledge in key physical literacy variables and confidence in undertaking physical-literacy promoting activities with their child/children. Further, the majority of parents were highly motivated to apply learnings from the PLAYshop and undertake physical literacy activities with their child/children.

Consistent with findings of prior research (Barnes et al., 2015; Morgan, Lubans, Callister, et al., 2011; Morgan et al., 2019), our results suggest that a brief training workshop may positively influence parenting practices in regards to physical literacy. What is more, research has shown that the home environment impacts a child's motor skill development (Barnett, Hnatiuk, Salmon, \& Hesketh, 2019; Zeng et al., 2019) and RCTs have further linked parent-focused interventions with improvements in child's FMS (Morgan et al., 2019) and physical activity (Morgan, Lubans, Callister, et al., 2011; Morgan et al., 2019). This has important implications seeing as physical literacy is a lifelong journey that impacts numerous health outcomes (Cairney et al., 2019). Educating parents may provide a viable means of influencing the physical literacy journey early in the life course. A more rigorous assessment of the PLAYshop via a RCT is needed to determine its efficacy.

Parents and workshop facilitators reported numerous strengths of the PLAYshop content and delivery, including its usefulness, convenience, and ability to elicit enthusiasm from both parents and children. Further, the workshop brevity, ease of delivery, and low supplies required makes it a realistic public health intervention in an era where resources are often scarce. However, despite these strengths, several implementation barriers were noted (e.g., distracting children, difficulty recruiting parents, and unfavorable delivery spaces). Fortunately, these challenges were exposed in this study and may be mitigated by modifications. For example, an additional facilitator to engage children during parental learning might lessen the distraction - a method successfully employed for the HDHK fatherchild practical sessions (Morgan, Lubans, Callister, et al., 2011). 
This study has numerous limitations including the small number of participants (largely due to recruitment challenges) and lack of a control group. However, this is common of feasibility studies whose primary purpose is to determine whether future definitive trials of an intervention should take place and if so, what this trial should like (Blatch-Jones, Pek, Kirkpatrick, \& Ashton-Key, 2018). Another limitation is the possibility of selection bias due to the use of self-recruitment methods: parents that were engaged with physical activity may have been more likely to enroll in the study. Future research is needed to determine how to recruit parents who are less engaged with physical activity for a more representative sample. Lastly, this study is limited by the short time period between baseline and follow-up data collection; with post-workshop surveys conducted the day following parent participation in the workshop. Longer term follow-up is needed to determine if the effects seen immediately following intervention delivery are maintained. Strengths of the study included the workshop delivery with real world partners in the context in which potential scale-up would occur.

\section{Conclusion}

The PLAYshop appeared feasible and improved parent self-efficacy to promote physical literacy with their child/children, although recruitment was challenging. Based on these positive results, the planning of a future full-scale RCT is currently underway and outcomes from this study will be used to inform modifications to improve workshop implementation and impact.

This study addresses an important research gap and is a valuable preliminary step in the development, testing and delivery of an intervention to promote childhood physical literacy. It contributes to the broader physical literacy movement that strives for children to have "the motivation, confidence, knowledge, skills, and fitness necessary to enjoy a physically active lifestyle" (Longmuir \& Tremblay, 2016).

\section{Abbreviations}

IPLA: International Physical Literacy Association; HDHK: Healthy Dads Healthy Kids; DADEE: Dads and Daughters Exercising and Empowered; FMS: Fundamental movement skills; RCT: Randomized controlled trial; BCW: Behavior Change Wheel

\section{Declarations}

Ethics approval and consent to participate: This study received human research ethics approval from the University of Victoria approval (\#16-444) and University of Alberta (\#00093764).

Consent for publication: Not applicable.

Availability of data and materials: The datasets used and/or analysed during the current study are available from the corresponding author on reasonable request.

Competing interests: The authors declare that they have no competing interests.

Funding: VC is supported by a Canadian Institutes of Health Research (CIHR) New Investigator Salary award. Island Health Wellness grant funding supported CW, KR and KM for workshop and evaluation implementation in three sites.

Authors' contributions: CL drafted the manuscript. PJN and CW conceived and developed the intervention concept. PJN guided the design and piloting of the intervention. CW, CL, PJN, KR implemented the intervention, PJN and VC oversaw the evaluation and data collection. CL, $\mathrm{KR}, \mathrm{KM}$ and MP collected and analysed the data. PJN and VC interpreted the data. All authors contributed to reviewing, editing and approving the final version of the paper.

Acknowledgements: We would like to acknowledge the contribution of all of the decision-makers and staff of various partner agencies involved in recruitment and implementation (Pacific Institute of Sport Excellence (PISE), School District 62, Takhini Elementary School, Yukon Territory Department of Education, Gorge and Saanich Fusion Soccer Associations, Island Health, Westshore Recreation and Parks Association); without their contributions and expertise this initiative and evaluation would have been impossible. We would also like to acknowledge Island Health funding for the Fostering Resilience through Physical Literacy Project in School District 62 through which three workshops were funded. We thank workshop leaders from PISE for their role in workshop delivery. Finally, we would like to acknowledge all of the parents and children that agreed to participate in the evaluation without whom this project could not have been carried out.

\section{References}


Aubert, S., Barnes, J. D., Abdeta, C., Nader, P. A., Adeniyi, A. F., Aguilar-Farias, N., . . Cardon, G. (2018). Global matrix 3.0 physical activity report card grades for children and youth: results and analysis from 49 countries. Journal of physical activity and health, 15(s2), S251S273.

Bandura, A. (1986). Social foundations of thought and action. Englewood Cliffs, NJ, 1986.

Barnes, A. T., Plotnikoff, R. C., Collins, C. E., \& Morgan, P. J. (2015). Feasibility and preliminary efficacy of the MADE4Life program: a pilot randomized controlled trial. Journal of Physical Activity and Health, 12(10), 1378-1393.

Barnett, L. M., Hnatiuk, J. A., Salmon, J., \& Hesketh, K. D. (2019). Modifiable factors which predict children's gross motor competence: a prospective cohort study. International Journal of Behavioral Nutrition and Physical Activity, 16(1), 129.

Barnett, L. M., Stodden, D., Cohen, K. E., Smith, J. J., Lubans, D. R., Lenoir, M., . . Dudley, D. (2016). Fundamental movement skills: An important focus. Journal of Teaching in Physical Education, 35(3), 219-225.

Blatch-Jones, A. J., Pek, W., Kirkpatrick, E., \& Ashton-Key, M. (2018). Role of feasibility and pilot studies in randomised controlled trials: a cross-sectional study. BMJ Open, 8(9), e022233.

Brown, H., Atkin, A., Panter, J., Wong, G., Chinapaw, M. J., \& Van Sluijs, E. (2016). Family-based interventions to increase physical activity in children: a systematic review, meta-analysis and realist synthesis. Obesity reviews, 17(4), 345-360.

Cairney, J., Dudley, D., Kwan, M., Bulten, R., \& Kriellaars, D. (2019). Physical literacy, physical activity and health: Toward an evidenceinformed conceptual model. Sports Medicine, 49(3), 371-383.

Carson, V., Lee, E.-Y., Hewitt, L., Jennings, C., Hunter, S., Kuzik, N., . . Gray, C. (2017). Systematic review of the relationships between physical activity and health indicators in the early years (0-4 years). BMC public health, 17(5), 854.

Craigie, A. M., Lake, A. A., Kelly, S. A., Adamson, A. J., \& Mathers, J. C. (2011). Tracking of obesity-related behaviours from childhood to adulthood: a systematic review. Maturitas, 70(3), 266-284.

Davison, K. K., Li, K., Baskin, M. L., Cox, T., \& Affuso, O. (2011). Measuring parental support for children's physical activity in white and African American parents: The Activity Support Scale for Multiple Groups (ACTS-MG). Preventive medicine, 52(1), 39-43. doi:10.1016/j.ypmed.2010.11.008

Edwards, L. C., Bryant, A. S., Keegan, R. J., Morgan, K., \& Jones, A. M. (2017). Definitions, foundations and associations of physical literacy: a systematic review. Sports Medicine, 47(1), 113-126.

Gale, N. K., Heath, G., Cameron, E., Rashid, S., \& Redwood, S. (2013). Using the framework method for the analysis of qualitative data in multi-disciplinary health research. BMC medical research methodology, 13(1), 117. doi:10.1186/1471-2288-13-117

Hesketh, K. R., Lakshman, R., \& van Sluijs, E. M. (2017). Barriers and facilitators to young children's physical activity and sedentary behaviour: a systematic review and synthesis of qualitative literature. Obesity reviews, 18(9), 987-1017.

Hesketh, K. R., O’Malley, C., Paes, V. M., Moore, H., Summerbell, C., Ong, K. K., . . van Sluijs, E. M. (2017). Determinants of change in physical activity in children 0-6 years of age: a systematic review of quantitative literature. Sports Medicine, 47(7), 1349-1374.

IPLA, I. P. L. A. (2017). IPLA definition Retrieved from https://www.physical-literacy.org.uk/

Jurbala, P. (2015). What is physical literacy, really? Quest, 67(4), 367-383.

Kohl 3rd, H. W., Craig, C. L., Lambert, E. V., Inoue, S., Alkandari, J. R., Leetongin, G., . . Group, L. P. A. S. W. (2012). The pandemic of physical inactivity: global action for public health. The lancet, 380(9838), 294-305.

Longmuir, P. E., \& Tremblay, M. S. (2016). Top 10 research questions related to physical literacy. Research Quarterly for Exercise and Sport, $87(1), 28-35$.

Love, R., Adams, J., \& van Sluijs, E. M. (2019). Are school-based physical activity interventions effective and equitable? A meta-analysis of cluster randomized controlled trials with accelerometer-assessed activity. Obesity reviews, 20(6), 859-870. 
Martin-Biggers, J., Spaccarotella, K., Hongu, N., Alleman, G., Worobey, J., \& Byrd-Bredbenner, C. (2015). Translating it into real life: a qualitative study of the cognitions, barriers and supports for key obesogenic behaviors of parents of preschoolers. BMC public health, 15(1), 1-14.

Messing, S., Rütten, A., Abu-Omar, K., Ungerer-Röhrich, U., Goodwin, L., Burlacu, I., \& Gediga, G. (2019). How Can Physical Activity Be Promoted Among Children and Adolescents? A Systematic Review of Reviews Across Settings. Frontiers in public health, 7, 55-55.

Metcalf, B., Henley, W., \& Wilkin, T. (2012). Effectiveness of intervention on physical activity of children: systematic review and metaanalysis of controlled trials with objectively measured outcomes (EarlyBird 54). BMJ : British Medical Journal, 345, e5888.

doi:10.1136/bmj.e5888

Michie, S., Van Stralen, M. M., \& West, R. (2011). The behaviour change wheel: a new method for characterising and designing behaviour change interventions. Implementation science, 6(1), 42.

Morgan, P. J., Lubans, D. R., Callister, R., Okely, A. D., Burrows, T. L., Fletcher, R., \& Collins, C. E. (2011). The 'Healthy Dads, Healthy Kids' randomized controlled trial: efficacy of a healthy lifestyle program for overweight fathers and their children. International journal of obesity, 35(3), 436-447.

Morgan, P. J., Lubans, D. R., Plotnikoff, R. C., Callister, R., Burrows, T., Fletcher, R., . . Clay, V. (2011). The'Healthy Dads, Healthy Kids' community effectiveness trial: study protocol of a community-based healthy lifestyle program for fathers and their children. BMC public health, 11(1), 876.

Morgan, P. J., Young, M. D., Barnes, A. T., Eather, N., Pollock, E. R., \& Lubans, D. R. (2019). Engaging fathers to increase physical activity in girls: the "dads and daughters exercising and empowered"(DADEE) randomized controlled trial. Annals of Behavioral Medicine, 53(1), 3952.

Rhodes, R. E., Perdew, M., \& Malli, S. (2020). Correlates of Parental Support of Child and Youth Physical Activity: a Systematic Review. International Journal of Behavioral Medicine, 1-11.

Rhodes, R. E., \& Rebar, A. L. (2017). Conceptualizing and Defining the Intention Construct for Future Physical Activity Research. Exercise and Sport Sciences Reviews, 45(4), 209-216. doi:10.1249/jes.0000000000000127

Richard, J. K., Lisa, M. B., Dean, A. D., Richard, D. T., David, R. L., Anna, S. B., . . John, R. E. (2019). Defining Physical Literacy for Application in Australia: A Modified Delphi Method. Journal of Teaching in Physical Education, 38(2), 105-118. doi:10.1123/jtpe.2018-0264 $10.1123 /$ jtpe.2018-0264

Smith, B. J., Grunseit, A., Hardy, L. L., King, L., Wolfenden, L., \& Milat, A. (2010). Parental influences on child physical activity and screen viewing time: a population based study. BMC public health, 10(1), 593.

Sport for Life. (2019). Developing Physical Literacy: Building a New Normal for all Canadians.

Tremblay, M. S., Costas-Bradstreet, C., Barnes, J. D., Bartlett, B., Dampier, D., Lalonde, C., . . Patton, R. (2018). Canada's Physical Literacy Consensus Statement: process and outcome. BMC public health, 18(2), 1034.

Tremblay, M. S., LeBlanc, A. G., Carson, V., Choquette, L., Connor Gorber, S., Dillman, C., . . Janssen, I. (2012). Canadian sedentary behaviour guidelines for the early years (aged 0-4 years). Applied Physiology, Nutrition, and Metabolism, 37(2), 370-380.

World Health Organization \& ExpandNet. (2011). Beginning with the end in mind: planning pilot projects and other programmatic research for successful scaling up. Retrieved from https://apps.who.int/iris/bitstream/handle/10665/44708/9789241502320_eng.pdf;jsessionid=CDF1F473BBB529B89F2227E9E9CC0411? sequence $=1$

Zeng, N., Johnson, S. L., Boles, R. E., \& Bellows, L. L. (2019). Social-ecological correlates of fundamental movement skills in young children. Journal of sport and health science, 8(2), 122-129.

\section{Figures}




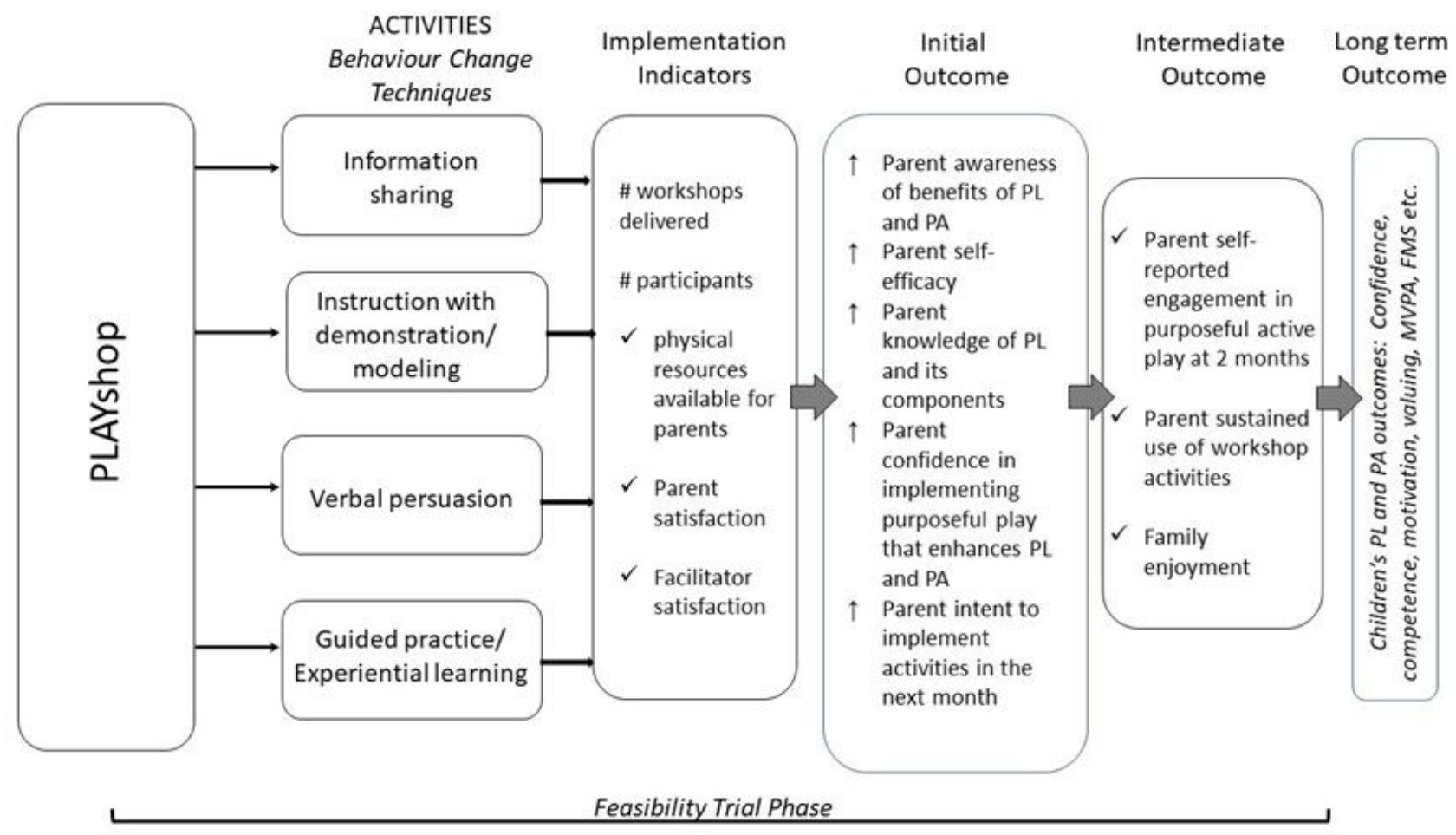

Figure 1

PLAYshop program logic model and components included within the feasibility trial phase

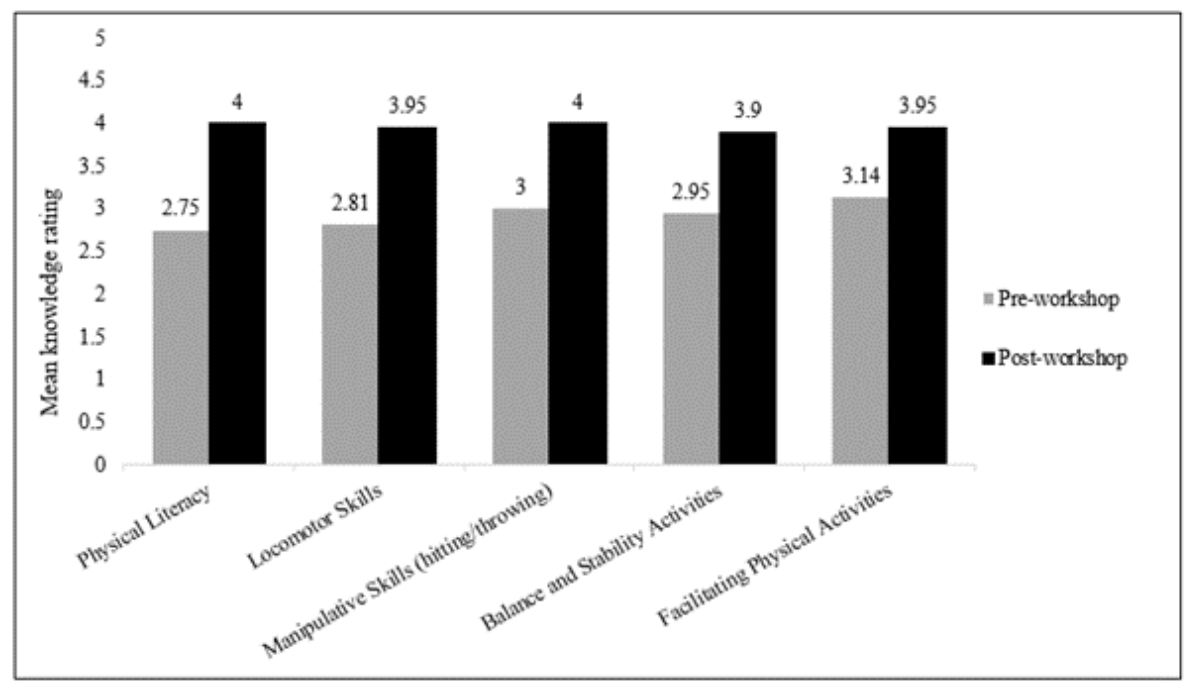

Figure 2

Parents' self-reported level of physical literacy knowledge pre-and post-workshop 


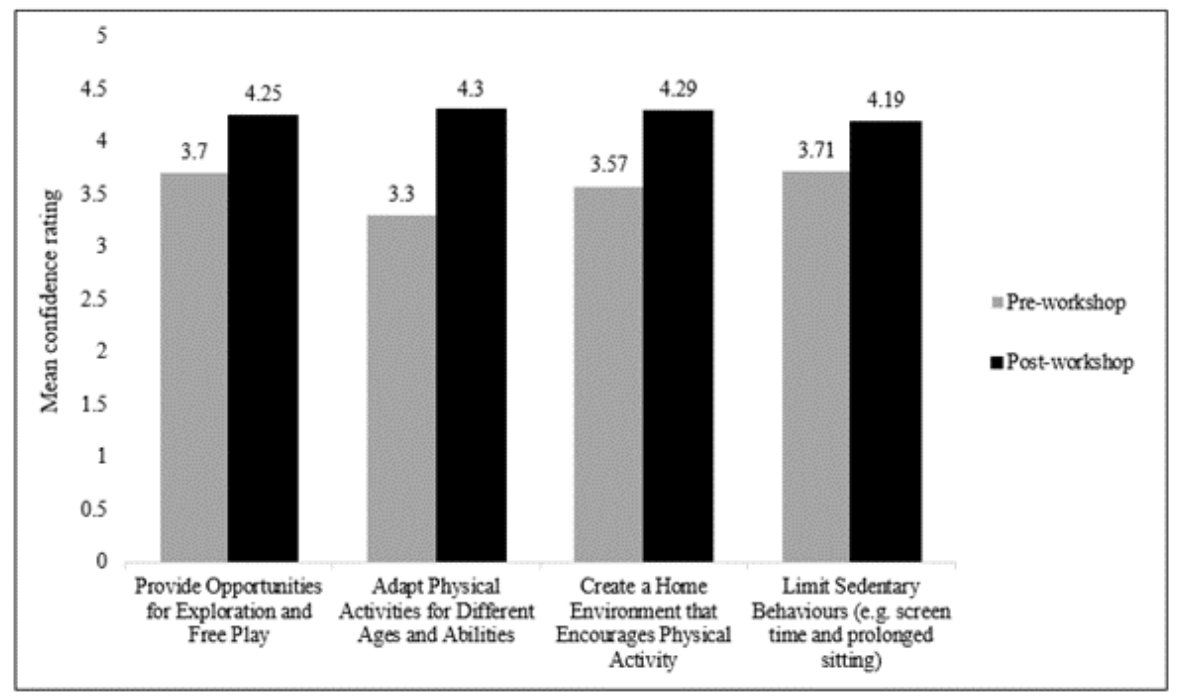

\section{Figure 3}

Parents' self-reported level of confidence to carry out key PLAYshop teachings pre- and post-workshop

\section{Supplementary Files}

This is a list of supplementary files associated with this preprint. Click to download.

- PLAYshopMinimumStandardsofReportingChecklist.docx 